\title{
The Influence of Shell Mold Composition on the As-cast Macro- and Micro-structure of Thin-Walled IN713C Superalloy Castings
}

\author{
Łukasz Rakoczy, Małgorzata Grudzień-Rakoczy, and Rafał Cygan
}

\author{
(Submitted September 28, 2018; in revised form February 21, 2019; published online May 23, 2019)
}

\begin{abstract}
In the investment casting process, the building of ceramic layers around the wax pattern is the main timeconsuming stage. Increasing their number ensures sufficient mechanical properties, but also lengthens the whole process, including drying time and preheating of the mold. Four molds for casting Ni-based superalloy IN713C were strengthened by glass fibers, included in the slurry, and metal powder, of $\mathrm{Al}, \mathrm{Cu}$, $\mathrm{Fe}$ or $\mathrm{Ni}$, in the coverage. Castings were subjected to microstructural investigations in order to find out if the new design can be promising for the manufacture of jet engine components. Bend tests revealed that the green strengths of all new molds were higher, at least 3.65 MPa, than that of the unmodified molds, 3.0 MPa. Optical microscopy revealed that the composition of a mold had a strong influence on stereological parameters of equiaxed IN713C grains. Microstructural observation and hardness measurements of castings revealed differences in the volume fraction of strengthening phases, porosity and hardness. The microstructure due to the complex chemical composition of IN713C consisted of several phases including ternary eutectics as a consequence of $\mathrm{L} \rightarrow \gamma+\mathrm{Ni}_{7} \mathrm{Zr}_{2}+(\mathrm{Nb}, \mathrm{Zr}) \mathrm{C}$.
\end{abstract}

Keywords aviation, glass fibers, investment casting, metal powder, shell mold

\section{Introduction}

Ni-based superalloys are characterized by high mechanical strength and resistance to creep at high temperatures, which is ensured by their complex chemical composition, microstructure and technological process. One of these alloys is precipitationstrengthened Inconel 713C which possesses excellent strength up to $980{ }^{\circ} \mathrm{C}$ (Ref 1-4). It is widely used for rotating and nonrotating components, namely low-pressure turbine blades and vane clusters in the new generation aircraft jet engines GP7200 (Ref 5, 6). The complex geometry of these components effectively does not allow machining. Investment casting (IC) is an extremely important technique for such fabrication because of its ability to obtain complex geometries, dimensionally very accurate, with an excellent surface finish. Taking

This article is an invited submission to JMEP selected from presentations at the 73rd World Foundry Congress and has been expanded from the original presentation. 73WFC was held in Krakow, Poland, September 23-27, 2018, and was organized by the World Foundry Organization and Polish Foundrymen's Association.

Lukasz Rakoczy, Department of Physical and Powder Metallurgy, Faculty of Metals Engineering and Industrial Computer Science, AGH University of Science and Technology, Av. Mickiewicza 30, 30-059 Cracow, Poland; Malgorzata Grudzień-Rakoczy, Lukasiewicz Research Network-Foundry Research Institute, ul. Zakopianska 73, 30-418 Cracow, Poland; and Rafal Cygan, Investment Casting Division CPP-Poland, Consolidated Precision Products Corp. (CPP), ul. Hetmanska 120, 35-078 Rzeszow, Poland. Contact e-mails: lrakoczy@agh.edu.pl, rafal.cygan@cppcorp.com into account the aviation safety requirement, these complicated castings must meet all quality standards, which in this case are highly strict (Ref 7-9). The various stages involved in the IC process are the creation of a disposable wax pattern, construction of several ceramic layers around the wax pattern, dewaxing and firing the mold and metal pouring into the mold under vacuum protection (Fig. 1).

The layers are usually made from the following basic ingredients: binder, refractory filler, additives (e.g., for stabilizing $\mathrm{pH}$ ) and stucco powders. In the forming process, binders perform particularly important functions, which include: ensuring appropriate strength before firing, regulating the properties of slurries and preventing the sedimentation of solid particles (Ref 10, 11). The dimensional changes of the molds during dewaxing, melt pouring and solidifying strongly depend on the green strength and elevated temperature strength. The high strength of ceramic molds for complex and large jet engines components is usually achieved by increasing thickness. On the other hand, low permeability, cooling rate and collapsibility of molds result mainly from the excessively large thickness of the layers (Ref 12). Additionally, the high number of layers prolong the drying, dewaxing, firing and preheating time, which is undesirable. Molds should be adequately porous and gas permeable, required to evacuate air and other entrapped gases promptly during melt pouring. For these reasons, some research has been undertaken to develop a fabrication method for reinforcing thin molds (Ref 13-15). One trend in the development of binders in investment casting is the introduction of ceramic or polymer fibers in the slurry for increasing mold strength (Ref 13). The literature data indicate that the ceramic fibers can significantly improve also the gas permeability of molds (Ref 16). Alumino-silicate fibers in the slurry were tested by Maity and Maity (Ref 17) up to a concentration of 0.66 wt.\%. Their research indicated a strong increase in modulus of rupture for the specimens as the concentration of fibers increased. An important stage in the investment casting 
process is also preheating the ceramic molds. For a typical mold consisting of nine layers, the time of heating up to a design preheat temperature is $100 \mathrm{~min}$ (Ref 18). Therefore, it seems reasonable to initiate research aimed to shorten this time. One way to shorten this time is to reduce the number of layers; however, this is not always possible due to the lowering of the mechanical properties of the mold. Therefore, a different solution was proposed, the addition of metal powders to the backup coat to increase the thermal conductivity of the molds. At the same time, it should be noted that the open literature lacks information on the influence of such molds on the primary microstructure of the superalloys used in aircraft components. In this work, new ceramic molds strengthened by glass fibers and metal powders (Ref 19) were fabricated and utilized in the investment casting of Inconel 713C. The main aim was to investigate the influence of selected mold variant on the stereological parameters of equiaxed grains, segregation of alloying elements and the morphology of primary constituents.

\section{Experimental Procedure}

The Inconel 713C nickel-based superalloy "master heat" was used as the casting and the gating system. Chemical composition designated by optical emission spectroscopy (OES) is presented in Table 1 .
The molds were fabricated in the Investment Casting Division of Consolidated Precision Products Corp., and all technological conditions were as similar as possible to internal standards accepted by aerospace customers. Wax pattern plates with dimensions $105 \mathrm{~mm} \times 65 \mathrm{~mm} \times 4 \mathrm{~mm}$ with $H$-type gating system were combined into a set. Four vents were prepared in order to stabilize and strengthen the wax model and also for better wax melting. Five molds were fabricated by the "dip and stucco" technique in accordance with data in Table 2. Every layer was created by dipping the wax pattern into a slurry (binder and filler) and then covered by a coarse dry backup. The prime layer of every mold was the same in all variants, namely colloidal silica, polymeric acrylic emulsion and fillers. Layers 2-7 had a different composition in the modified mold (acrylic polymer emulsion containing additionally randomly distributed glass fibers). The geometry of raw wax assembly and after coating is shown in Fig. 2. The castings are marked in accordance with letters $\mathrm{Al}$ to $\mathrm{Ni}$, Table 2, according to the type of metal powder added to the coverage (unmodified casting is marked as B). Commercially available metal powders were used.

The molds after drying ( $48 \mathrm{~h}$ ) were subjected to dewaxing in a boiler clave, burning out to remove residual wax, and finally were covered by alumina silicate Fiberfrax ${ }^{\circledR}$ heat insulation. In order to compare the influence of glass fibers and metal powder on the green strength (after dewaxing) of ceramic molds, additional sets were made from which bend test samples were

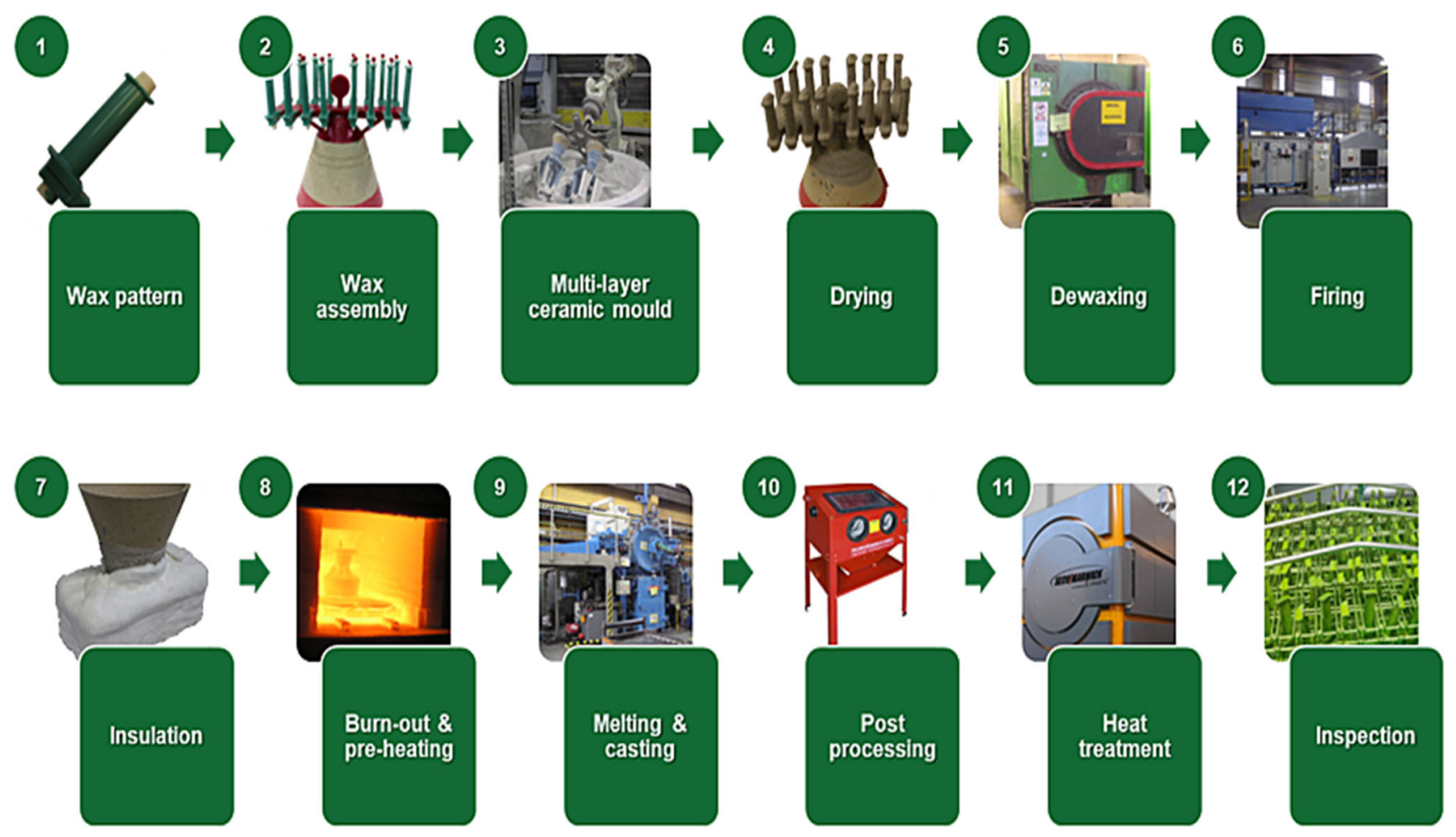

Fig. 1 Scheme of the investment casting process of the aircraft engines components

Table 1 Chemical composition of Inconel 713C

\begin{tabular}{lccccccccccc}
\hline Element & $\mathbf{C r}$ & Al & Mo & Nb & Ti & C & Zr & Co & B & Ni \\
\hline wt.\% & 14.24 & 5.93 & 4.29 & 2.45 & 0.92 & 0.11 & 0.08 & 0.04 & 0.012 & Bal. \\
\hline
\end{tabular}


Table 2 Composition of layers 2-7

\begin{tabular}{|c|c|c|c|c|c|}
\hline & & Calcium aluminate & & \multicolumn{2}{|c|}{ Backup layers +5 wt. $\%$ metal powder } \\
\hline "B" & Colloidal silica + Acrylic polymer emulsion & 0 & $3 \mathrm{Al}_{2} \mathrm{O}_{3} 2 \mathrm{SiO}_{2}$ (mullite) & Alumina silicate & Without metal powder \\
\hline "Al" & & 1.5 wt. $\%$ & $\mathrm{Al}_{2} \mathrm{O}_{3}$ & & $\mathrm{Al}$ \\
\hline "Cu”, & & & $\mathrm{SiO}_{2}$ & & $\mathrm{Cu}$ \\
\hline "Fe" & & & & & $\mathrm{Fe}$ \\
\hline "Ni" & & & & & $\mathrm{Ni}$ \\
\hline
\end{tabular}

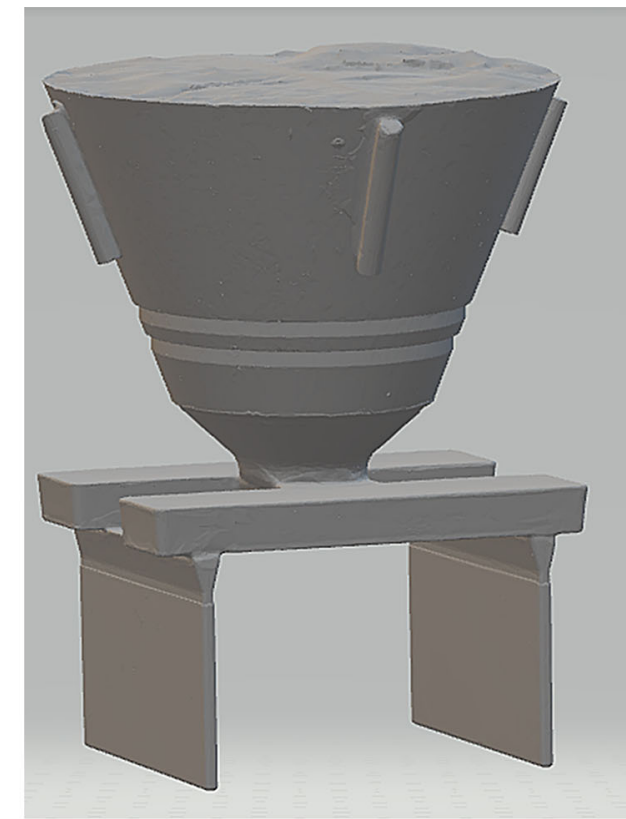

(a)

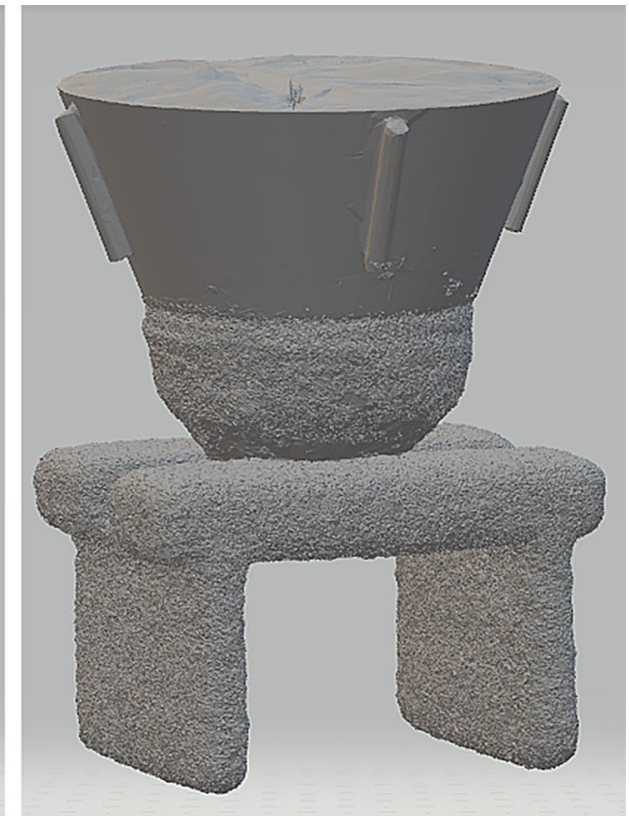

(b)

Fig. 2 Geometry of wax model: (a) before coating; (b) after coating

taken. The strength of mold samples was determined in a threepoint bend test (minimum of 20 samples for each variant). The measurements were carried out using Q TEST testing machine with a span $L$ equal to five times the average thickness (approx. $7 \mathrm{~mm}$ ) of the samples, i.e., $L=35 \mathrm{~mm}$. The samples were loaded at a speed of $1000 \mathrm{~mm} / \mathrm{min}$ up to fracture. The pouring process of Inconel 713C was carried out in the Research and Development Laboratory for Aerospace Materials at the Rzeszow University of Technology in a double-chamber vacuum oven VIMIC2E-DS/SC produced by ALD Vacuum Technology. Each ceramic mold was placed in the chamber of the furnace and preheated at $1250{ }^{\circ} \mathrm{C}$ for $100 \mathrm{~min}$. The $4-\mathrm{kg}$ ingot of the Inconel 713C superalloy was inductively melted in a vacuum of $2.9 \times 10^{-3} \mathrm{~Pa}$. The liquid superalloy was poured into molds at $1520{ }^{\circ} \mathrm{C}$ and subsequently displaced to the cooling zone of the furnace (in about $10 \mathrm{~s}$ ). It should be mentioned that differential scanning calorimetry (DSC) of fibers which was isolated from the binder indicated strong exothermic peak at $885{ }^{\circ} \mathrm{C}$. During solidification of castings, the cooling chamber was ventilated and the next mold was mounted inside the furnace. After solidification, the products were cooled to room temperature, the molds were broken, and cast plates were cut off. The surfaces of all plates were sandblasted and etched in the solution of $0.75 \mathrm{~g}$ molybdic acid,
$25 \mathrm{~mL}$ nitric acid and $25 \mathrm{~mL}$ hydrochloric acid in $25 \mathrm{~mL}$ water. Macrostructures of the castings recorded on an Optimus device were subjected to analysis by ImageJ commercial software (five images for one casting). The mean area, perimeter, size of grain (diameter of a circle with the same surface area) and number of grains per $\mathrm{cm}^{2}$ were calculated. Further microstructural observations were carried out on an optical microscope and scanning electron microscope equipped with (EDS) energy-dispersive xray spectrometer (accelerating voltage $20 \mathrm{kV}$ ). Microstructure images recorded on (LM) Leica DM4500 and SEM Phenom $\mathrm{XL}$ were subjected to threshold and binarization by ImageJ, and then, the area fraction of porosity, area fraction of carbides and volume fraction of $\gamma^{\prime}$ both in dendrite arms and interdendritic spaces were calculated. Minimum five images for each casting were used to calculate the stereological parameters. Samples were electrochemically etched in $10 \% \mathrm{CrO}_{3}$ solution. Segregation coefficient $k=\frac{C_{D}^{i}}{C_{I D}^{i}}$ (concentration of alloying element in the centerline of dendrite divided by concentration in the interdendritic space) was calculated based on the 20 measurements in different locations. Each EDS linear distribution of alloying elements included 512 measurements on the selected line. Vickers hardness (HV10) measurements (10 for each casting) were carried out on Zwick/Roell device. 


\section{Results and Discussion}

\subsection{Green Strength of Molds}

Bend strengths of the unmodified and fiber- and metalreinforced molds are shown in Table 3. There is a clear indication that the fiber- and metal-free mold has a lower green strength than all the reinforced molds. For mold $\mathrm{Ni}$, the strength, $3.94 \mathrm{MPa}$, was higher by more than $30 \%$ from unmodified mold B. Addition of glass fibers and metal powders also led to more uniform bend strengths of the modified molds. Obtaining more repeatable results is very beneficial to the production of castings.

According to the Maity and Maity (Ref 17), the reason for the increased strength was crack growth resistance ensured by the fibers, located mostly parallel to the layers, perpendicular to the direction of cracking propagation. Based on the results of Wang (Ref 20), the exothermic peak at $885{ }^{\circ} \mathrm{C}$ obtained during DSC corresponded to the crystallization of fibers. During firing of mold and subsequent melt pouring, the phase transformation solid state (metal powders) $\rightarrow$ liquid also occurred. Designed melt-pouring temperature was $1520^{\circ} \mathrm{C}$ and so higher than the melting point of $\mathrm{Al}\left(660^{\circ} \mathrm{C}\right), \mathrm{Cu}\left(1085^{\circ} \mathrm{C}\right)$ and $\mathrm{Ni}\left(1455^{\circ} \mathrm{C}\right)$, whereas slightly lower than for $\mathrm{Fe}\left(1538{ }^{\circ} \mathrm{C}\right)$ (Ref 21). A previous investigation (Ref 18) showed that the maximum temperature in the second layer during investment casting process can be lower approximately $150{ }^{\circ} \mathrm{C}$ than the pouring temperature. This indicates that the $\mathrm{Fe}$ and $\mathrm{Ni}$ existed as solid particles.

\subsection{Stereological Parameters of Castings Structure}

The macrostructure of the castings produced using molds reinforced with glass fibers and metal powders is shown in Fig. 3. The thin-walled plates were of very high quality, so the lost-wax casting process was conducted correctly. Casting defects as cracks or misruns were not observed. It supposed that the presence of metal powders in the ceramic molds increased the thermal conductivity, and thus the cooling times of the molds could be shorter. Very high heat dissipation during pouring and solidification of castings favors undercooling and so consequently, the formation of a chill zone structure. These columnar grains were not revealed, so appropriate heat transfer after pouring was obtained. To compare the stereological parameters of the macrostructure of castings, image analysis was performed and the results are recorded in Table 4. The addition of $\mathrm{Ni}$ or $\mathrm{Cu}$ to the coverage led to slight grain refinement. The largest mean grain area was obtained in the casting $\mathrm{Al}$; however, the large standard deviation indicates that the structure was not uniform. Among the large grains, very small ones were present. The most uniform mean area and mean perimeter of the grains were observed in the Ni casting. The standard deviation for the mean area $23.72 \mathrm{~mm}^{2}$ was $19.49 \mathrm{~mm}^{2}$, while for the mean perimeter $24.07 \mathrm{~mm}$, it was $11.56 \mathrm{~mm}$. The difference of mean grain size between the

Table 3 Green strength of molds

\begin{tabular}{lccccc}
\hline Shell mold & B & Al & Cu & Fe & Ni \\
\hline Strength, $\mathrm{MPa}$ & $3.0( \pm 1.5)$ & $3.65( \pm 0.89)$ & $3.74( \pm 0.91)$ & $3.66( \pm 0.85)$ & $3.94( \pm 1.0)$ \\
\hline
\end{tabular}
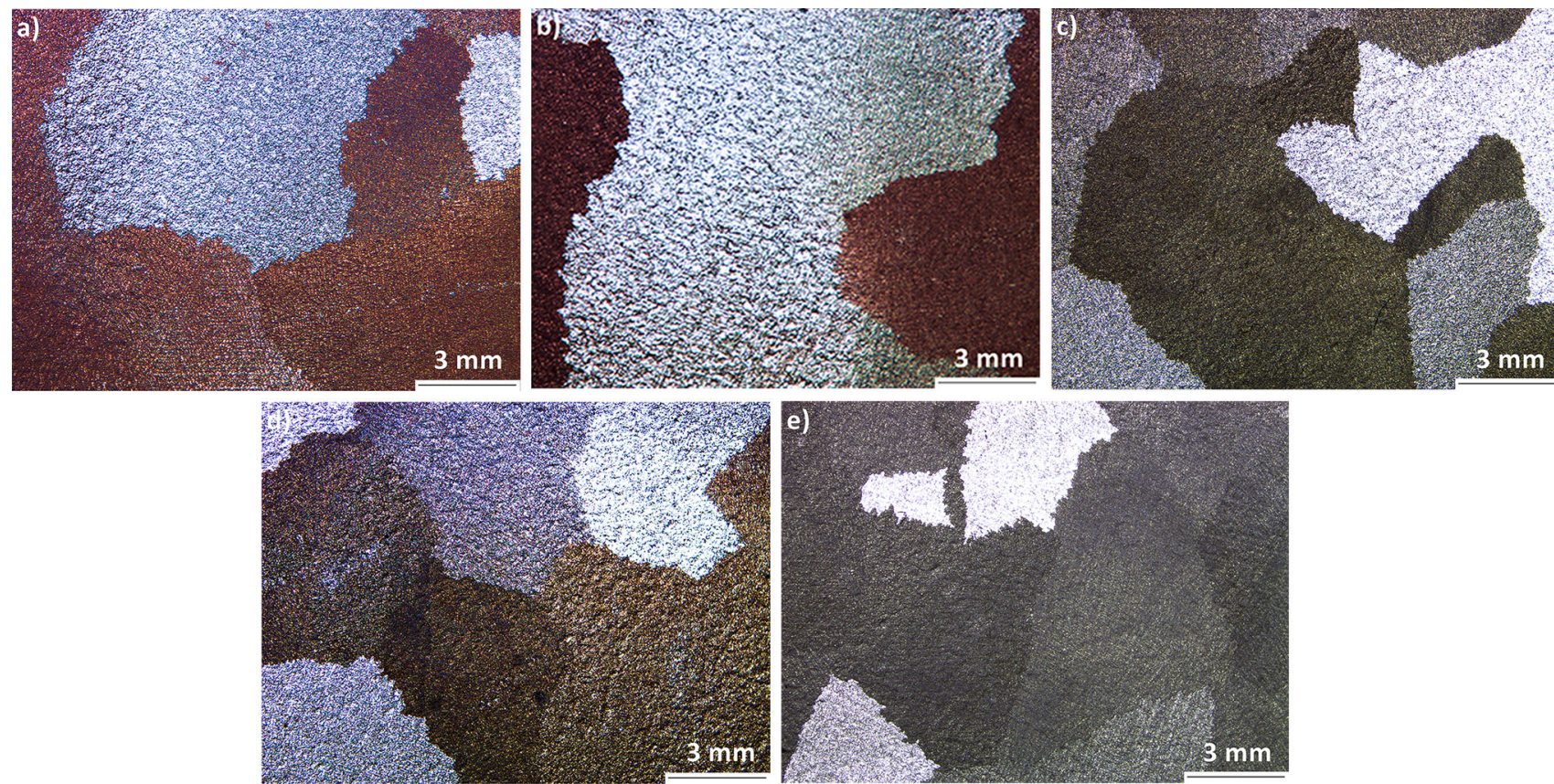

Fig. 3 Selected macrostructure of casting produced in mold: (a) $\mathrm{B}$; (b) $\mathrm{Al}$; (c) $\mathrm{Cu}$; (d) $\mathrm{Fe}$; (e) $\mathrm{Ni}$ 
Table 4 Results of macrostructure analysis

\begin{tabular}{lccccc}
\hline Mold & Mean area, $\mathbf{~ m m}^{\mathbf{2}}$ & Mean perimeter, $\mathbf{m m}$ & Mean grain size, $\mathbf{m m}$ & Range of grain size, mm & Number of grains per cm \\
\hline $\mathrm{B}$ & $31.96( \pm 29.63)$ & $25.81( \pm 13.68)$ & $5.60( \pm 3.04)$ & 10.09 & $3.19( \pm 0.53)$ \\
$\mathrm{Al}$ & $54.01( \pm 55.81)$ & $34.61( \pm 20.66)$ & $7.26( \pm 4.14)$ & 11.51 & $1.85( \pm 0.30)$ \\
$\mathrm{Cu}$ & $23.54( \pm 24.85)$ & $23.71( \pm 16.95)$ & $4.76( \pm 2.76)$ & 9.83 & $4.25( \pm 0.93)$ \\
$\mathrm{Fe}$ & $29.03( \pm 33.21)$ & $24.19( \pm 14.04)$ & $5.30( \pm 3.06)$ & 12.13 & $3.45( \pm 0.70)$ \\
$\mathrm{Ni}$ & $23.72( \pm 19.49)$ & $24.07( \pm 11.56)$ & $5.04( \pm 2.26)$ & 8.27 & $4.21( \pm 1.35)$ \\
\hline
\end{tabular}

Table 5 Secondary dendrite arm spacing in the molds

\begin{tabular}{lccccc}
\hline Mold & B & Al & Cu & Fe & Ni \\
\hline Mean value, $\mu \mathrm{m}$ & $82( \pm 10)$ & $74( \pm 8)$ & $63( \pm 5)$ & $74( \pm 7)$ & $80( \pm 5)$ \\
\hline
\end{tabular}

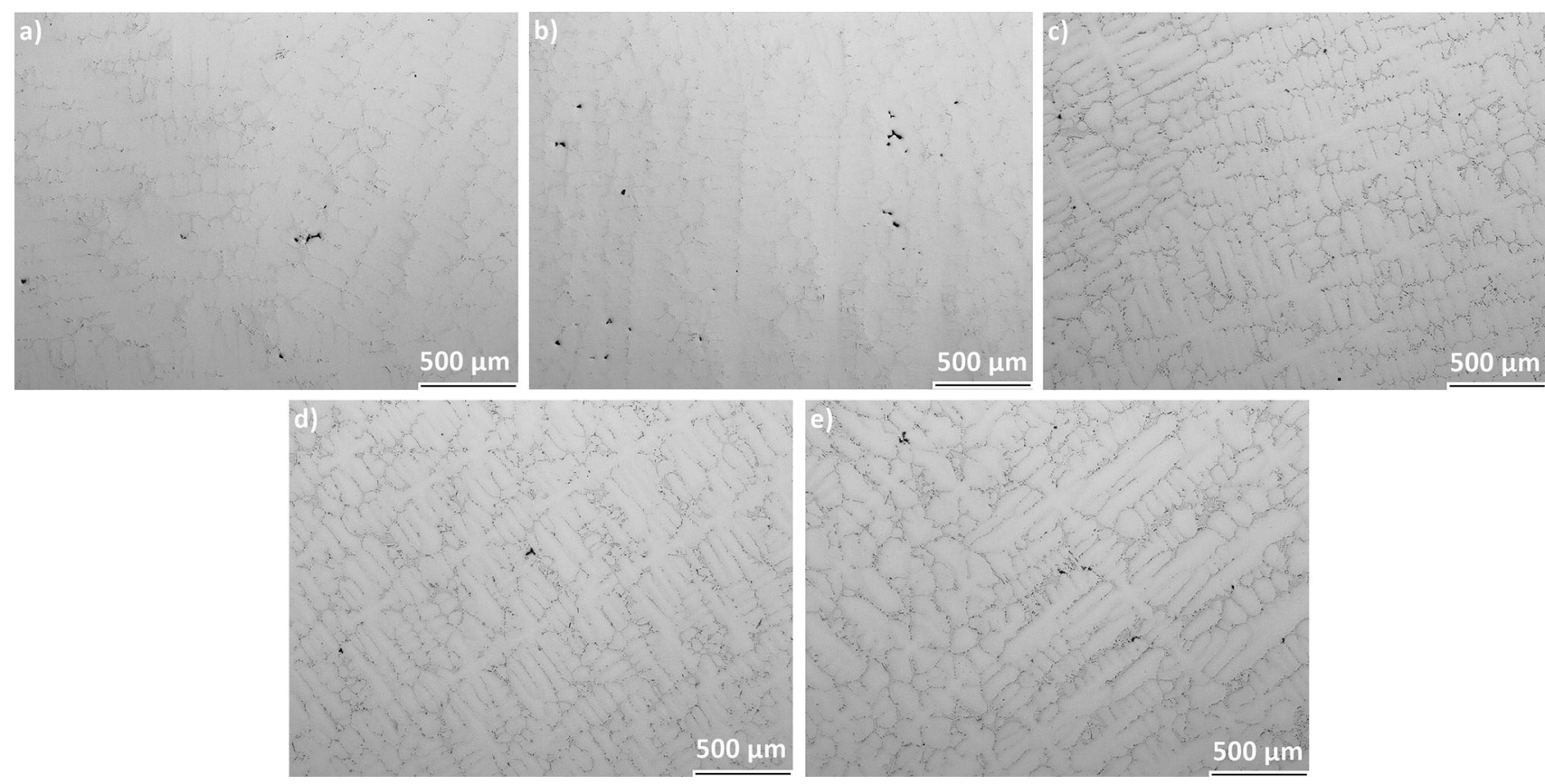

Fig. 4 Porosity of casting produced in mold: (a) B; (b) $\mathrm{Al}$; (c) $\mathrm{Cu}$; (d) $\mathrm{Fe}$; (e) $\mathrm{Ni}$

casting $\mathrm{Al}$ and the casting $\mathrm{Cu}$, characterized by a more refined structure, was less than $2.5 \mathrm{~mm}$.

Secondary dendrite arm spacing (SDAS) was measured, and the results are shown in Table 5. Strong correlation between SDAS and the variant of mold used was not found. The casting from unmodified mold was characterized by the largest mean SDAS. The average distance between the dendrite arms in the modified castings was in the range of 63-80 $\mu \mathrm{m}$. The lowest average value was achieved in the $\mathrm{Cu}$ castings, whereas the highest in the casting $\mathrm{Ni}$. The unmodified casting was characterized by the largest standard deviation of SDAS.

\subsection{Optical Microscopic and SEM Observations}

Microscopic examination of all specimens indicated the presence of irregularly distributed shrinkage porosity (Fig. 4), predominantly in the interdendritic regions. Their location indicated that porosity formed during the last stages of solidification, when capillary feeding becomes insufficient. Based on the unetched microstructures, the area fraction of porosity was calculated and results are shown in Fig. 5.

In the casting $\mathrm{B}$, the porosity was $0.095 \%$. Only in casting $\mathrm{Al}$, the porosity was higher $0.107 \%$. In the other modified castings, namely $\mathrm{Cu}, \mathrm{Fe}$ and $\mathrm{Ni}$, the porosity was much lower $0.044,0.029$ and $0.061 \%$, respectively. The investment casting of IN713C in the mold with the addition of glass fibers and Fe powder led to a threefold reduction in porosity. Subsequent reduction in porosity can be obtained by using hot isostatic pressing (HIP) treatment. According to the investigation focusing on the healing mechanism of K452 superalloy, porosity can be reduced through HIP even $82 \%$ (Ref 22). At least two factors have been proposed, which can control microporosity formation in superalloys: the volume fraction of residual liquid at the end of solidification, and the so-called cork effect associated with carbides formed near the liquidus 
temperature (Ref 23). In order to compare the fraction of porosity with the fraction of primary carbides in the castings, SEM observation of unetched specimens was carried out (Fig. 6). The largest volume fraction of carbides was calculated for casting Al, 1.05\%, which was characterized by the highest porosity (Fig. 7). The lowest volume of carbides was in casting $\mathrm{Fe}(0.72 \%)$ with the lowest porosity. For castings B, Cu and Fe, no such a clear relationship was recorded. Baldan (Ref 23) observed that the porosity level in DS200 + Hf alloy decreases with the increasing fraction of carbides, whereas the carbon content of IN100 was found to impair the soundness (Ref 23).

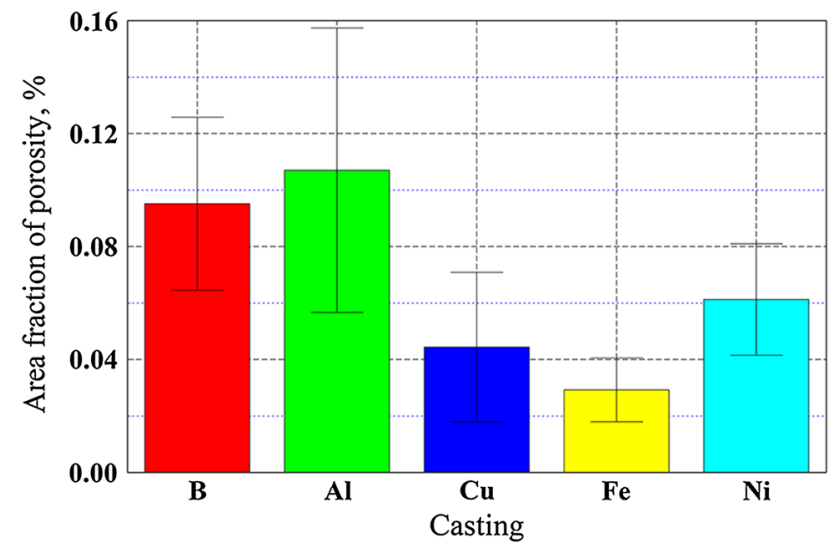

Fig. 5 Area fraction of porosity in castings
The contradictory relations indicate that the influence of one specific factor on microporosity incidence in Ni-based superalloy depends not only on the nature of this factor, but also on the whole chemical composition and segregation of alloying elements during solidification.

SEM examination of etched specimens indicated the presence of a dendritic microstructure typical of the as-cast state (Fig. 8). The microstructure of interdendritic regions in all castings was complex due to the presence of numerous constituents, which has been analyzed in detail (Sect. 3.5). The near-cubic-shaped precipitates of intermetallic $\gamma^{\prime}$ phase

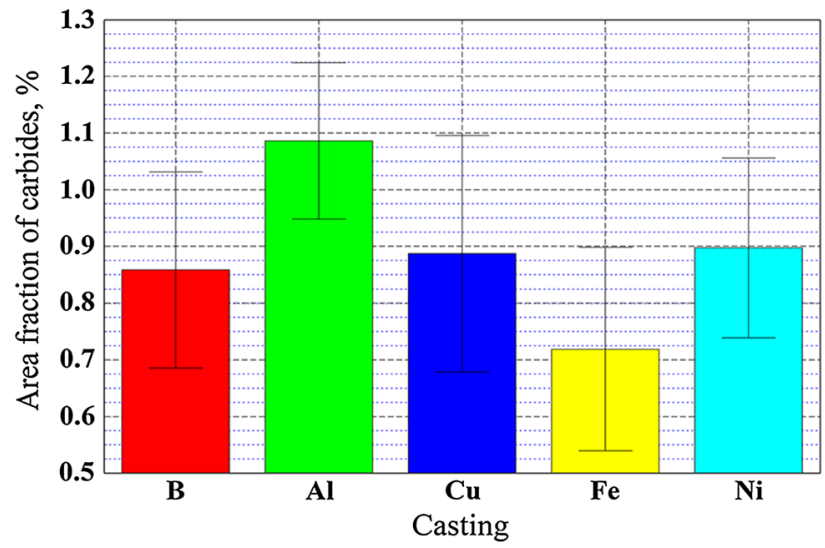

Fig. 7 Area fraction of carbides in castings
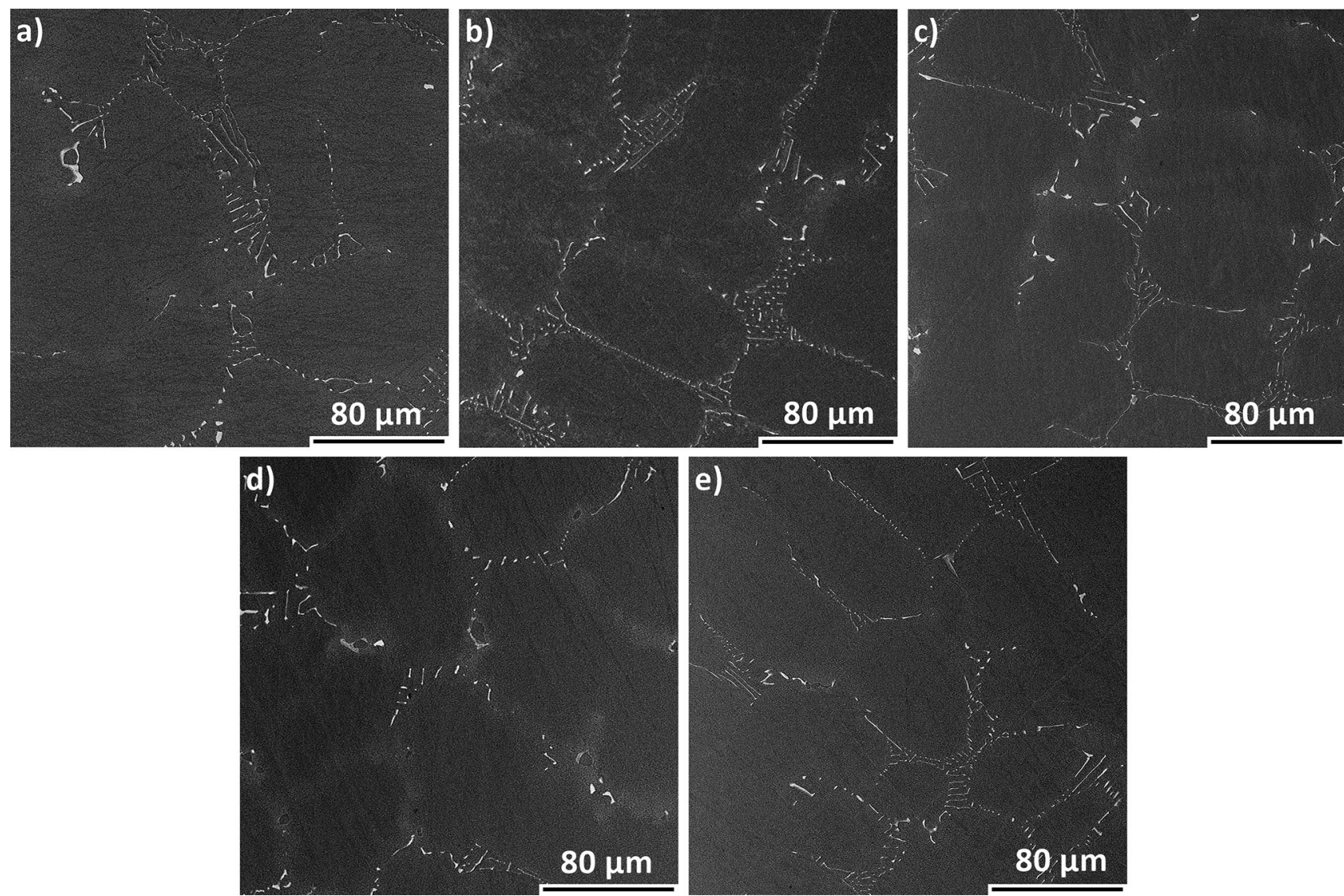

Fig. 6 Morphology of primary carbides in casting: (a) $\mathrm{B}$; (b) $\mathrm{Al}$; (c) $\mathrm{Cu}$; (d) $\mathrm{Fe}$; (e) $\mathrm{Ni}$ 

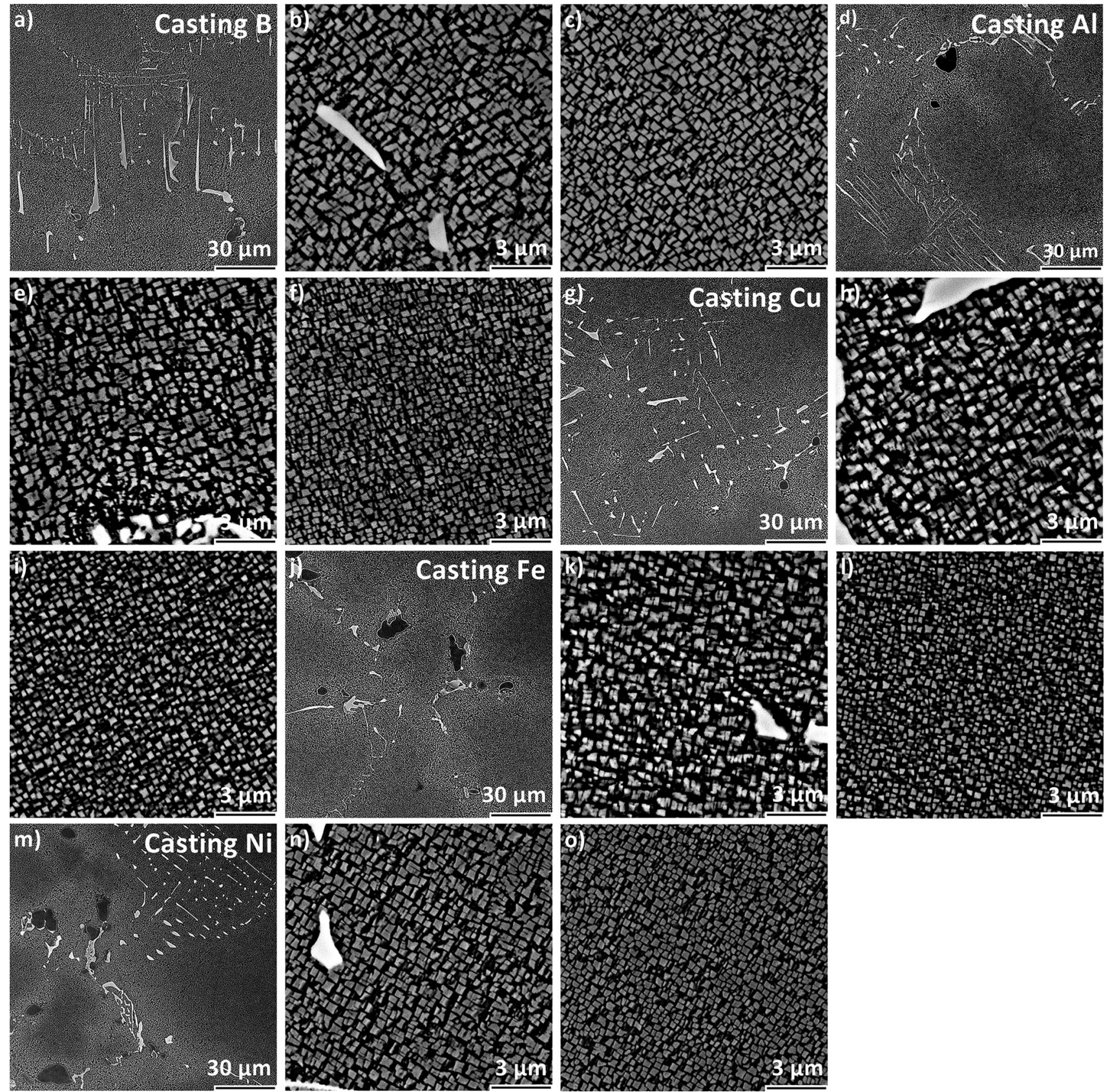

Fig. 8 Microstructure of Inconel 713C castings: (a, d, g, j, m) interdendritic spaces; (b, e, h, k, n) $\gamma^{\prime}$ in interdendritic space (c, f, i, l, o) $\gamma^{\prime}$ precipitates in dendrite arm

were surrounded by the $\gamma$ phase, while their size and morphology were different in dendrite arms and between them. This difference is related to the irregular distribution of alloying elements in the volume of castings, which affected the size of the $\gamma^{\prime}$ phase precipitates. The volume fraction of $\gamma^{\prime}$ phase also differed between the castings. Measurements were carried out in dendrite arms and interdendritic spaces, and the results are shown in Fig. 9. In each casting, the volume fraction of the $\gamma^{\prime}$ phase reached a higher value in the dendrite arms. The volume fraction of $\gamma^{\prime}$ phase in the dendrite arms of casting B was $49 \%$, while a lower value was only in the casting $\mathrm{Cu}, 46.5 \%$. The highest volume fraction of the $\gamma^{\prime}$ phase in the dendrite arms was obtained in the casting $\mathrm{Al}: 53.7 \%$. Thus, an increase of over $9 \%$ was reached in comparison with the casting B. Taking into account interdendritic spaces, the highest volume fraction of $\gamma^{\prime}$ phase was also obtained in the casting Al (48.5\%). Similar to the measurements in dendrite arms, the volume fractions of precipitates in castings $\mathrm{Fe}$ and $\mathrm{Ni}$ were higher than in the casting $\mathrm{B}$.

\subsection{Segregation Coefficient}

The average concentration of the main alloying elements in the dual-phase area $\left(\gamma+\gamma^{\prime}\right)$ in dendrite arms and the interdendritic spaces were measured using energy-dispersive x-ray spectroscometry. Microsegregation of alloying elements during solidification caused their concentrations in different regions to be quite different. In order to show irregular distribution of alloying elements between these regions, the coefficient 

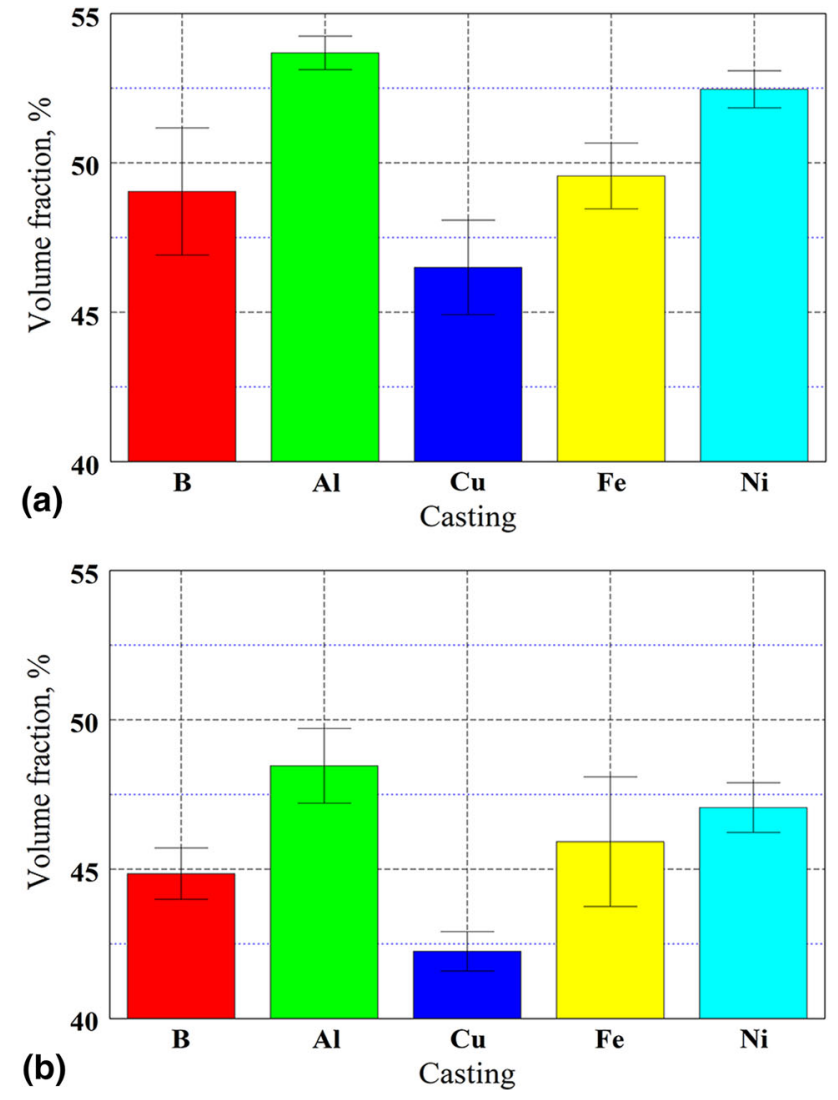

Fig. 9 Volume fraction of $\gamma^{\prime}$ in: (a) dendrite arms; (b) interdendritic spaces

$k=\frac{C_{D}^{i}}{C_{I D}^{i}}$, the ratio of the concentration of alloying element in the centerline of dendrites to the concentration in interdendritic spaces, was calculated and is presented in Fig. 10 for all castings.

Aluminum is the main $\gamma^{\prime}$ former in Ni-based superalloys. The highest $\mathrm{k}_{\mathrm{Al}}$ value was observed in the castings from molds designated as $\mathrm{B}$ and $\mathrm{Ni}$, namely 1.12 and 1.10 , although the standard deviation was also the highest for these variants. The lowest $k_{\mathrm{Al}}$ value and also standard deviation were obtained for the casting $\mathrm{Cu}$. Significantly lower segregation coefficients were observed when measuring the Ti contents. In all castings $k<1$, which indicates a significant enrichment in the interdendritic spaces in this alloying element. The lowest value was recorded for the Fe casting, while the highest for Al casting, and so $0.54 \leq k \leq 0.65$. Analysis of the distribution of $\mathrm{Nb}$ in the castings also indicated a significant increase in its concentration in interdendritic spaces. The lowest $k_{\mathrm{Nb}}$ was for the $\mathrm{Cu}$ casting; the highest for $\mathrm{Ni}$ casting, 0.56 and 0.71 , respectively. The distribution of Mo in the castings was much more uniform relative to $\mathrm{Ti}$ and $\mathrm{Nb}$. The obtained mean $k_{\mathrm{Mo}}$ values were in the range of 1.01-1.16. The highest $k_{\mathrm{Mo}}$ was for the casting from mold B (the standard deviation was also the highest), while the lowest was for the $\mathrm{Al}$ and $\mathrm{Ni}$ castings. Measurements of $\mathrm{Cr}$ concentration gave all $k_{\mathrm{Cr}}$ values higher than 1, so its content was higher in dendrite arms. By far, the highest $\mathrm{k}_{\mathrm{Cr}}$ was calculated for castings from molds $\mathrm{Fe}$ and $\mathrm{B}$, 1.38 and 1.37 , respectively. Resulted segregation leads to inhomogeneity of the coherence stresses and inhomogeneity of the thermal contraction during $\gamma^{\prime}$-precipitation. In order to decrease the irregular distribution of all alloying elements, a solution heat treatment is usually carried out. Segregation of alloying elements causes a misfit inhomogeneity, and hereby, it influences the primary creep of superalloys (Ref 24, 25).

\subsection{Morphology and Chemical Composition of the Primary Phases}

The segregation of the alloying elements during solidification led to the formation of many phases in interdendritic spaces of castings. Intensive observation and analysis indicated that, independently of casting variant, the same phases occurred in interdendritic spaces. The microstructure of these selected constituents and results of EDS analysis were presented, respectively, in Fig. 11 and 12.

Based on the microstructural features, it can be concluded that in the first stage of solidification, $\gamma$ phase is formed. During cooling, the solubility of elements like $\mathrm{Nb}, \mathrm{Mo}$, Ti and $\mathrm{C}$ in the existing matrix decreased, which induces their segregation at the $\gamma$ phase dendrite-interdendritic liquid interface. These conditions favor the precipitation of carbides which occurs in various forms, from blocky shaped to Chinese script, e.g., those in Fig. 8 and 11. All identified carbides were strongly enriched in $\mathrm{Nb}$, Mo and $\mathrm{Ti}$, which is clearly shown in Fig. 11(a). Nb forms MC-type carbides in superalloys, which are precipitated directly from the liquid according to $\mathrm{L} \rightarrow$

$\mathrm{MC}$ and $\mathrm{L} \rightarrow \gamma+\mathrm{MC}$ reactions (Ref 26). Precipitates formed via the first reaction were moved into interdendritic spaces by solidified $\gamma$ phase. Eutectic-type reaction also occurred at the final stage of Inconel 713C solidification, the $\mathrm{L} \rightarrow \gamma+\gamma^{\prime}$ reaction happened, and the gamma prime precipitates took up an irregular morphology as eutectic islands $\gamma /$ $\gamma^{\prime}$. Carbide formed through the eutectic reaction, in the close vicinity of constituent with lamellar morphology, is presented in Fig. 11(b). Microanalysis in the main core of this precipitate revealed an increased concentration of $\mathrm{Ni}$ and $\mathrm{Zr}$ (Fig. 12b). One of the important features of superalloys is the enhancement of creep strength when minute amounts of $\mathrm{Zr}$ and also B are added. Both these elements are in the investigated alloy: 0.012 wt.\% (B) and $0.08 \%(\mathrm{Zr})$. As their solubility in the $\gamma$ and $\gamma^{\prime}$ is very low, favorable conditions for the formation of intermetallic phases and borides exist. Transmission electron microscopy of IN713C (Ref 9) indicated that such lamellar precipitates were $\mathrm{Ni}_{7} \mathrm{Zr}_{2}$. According to the $\mathrm{Ni}-\mathrm{Zr}$ (Ref 27) binary diagram, $\mathrm{Ni}_{7} \mathrm{Zr}_{2}(\mathrm{mC} 36, \mathrm{C} 2 / \mathrm{m})$ is formed at $1438{ }^{\circ} \mathrm{C}$ through congruent reaction $\mathrm{L} \rightarrow \mathrm{Ni}_{7} \mathrm{Zr}_{2}$, and then, two peritectic reactions occur: at $1304{ }^{\circ} \mathrm{C}, \mathrm{L}+\mathrm{Ni}_{7} \mathrm{Zr}_{2} \rightarrow \mathrm{Ni}_{5} \mathrm{Zr}$ (cF24, F-43 m) and subsequently at $1181{ }^{\circ} \mathrm{C} \mathrm{L}+\mathrm{Ni}_{7} \mathrm{Zr}_{2} \rightarrow$ $\mathrm{Ni}_{21} \mathrm{Zr}_{8}$. Franke (Ref 27) indicated that only one eutectic reaction occurs with the formation of face-centered cubic FCC$\gamma, \mathrm{L} \rightarrow \gamma+\mathrm{Ni}_{5} \mathrm{Zr}$ at $1164{ }^{\circ} \mathrm{C}$. Thus, $\mathrm{Ni}_{7} \mathrm{Zr}_{2}$ phase can be present in the Inconel $713 \mathrm{C}$, but not in the form of eutectic $\gamma /$ $\mathrm{Ni}_{7} \mathrm{Zr}_{2}$, and its formation can be complex as the microstructure suggests. Residual liquid is enriched in $\mathrm{Zr}$ at the final stage of solidification reaction with the eutectic phase or primary $\gamma^{\prime}$ through a peritectic-type transformation $\mathrm{L}+\gamma^{\prime} \rightarrow \gamma+\mathrm{Ni}_{7} \mathrm{Zr}_{2}$ (Ref 28). Due to the complex chemical composition of $\mathrm{Ni}$ based superalloys, at the end of solidification, ternary eutectic transformation can take place. An example of ternary eutectic reaction which produces $\mathrm{Ni}_{7} \mathrm{Zr}_{2}$ was proposed (Ref 28), namely $\mathrm{L} \rightarrow \gamma+\mathrm{Ni}_{7} \mathrm{Zr}_{2}+\mathrm{Ni}_{5} \mathrm{Zr}$, but the $\mathrm{Ni}_{5} \mathrm{Zr}$ was not detected in IN713C. Similarly, in other Ni-based superalloys (IN100 and IN738), the presence of $\mathrm{Ni}_{7} \mathrm{Zr}_{2}$ phase was 

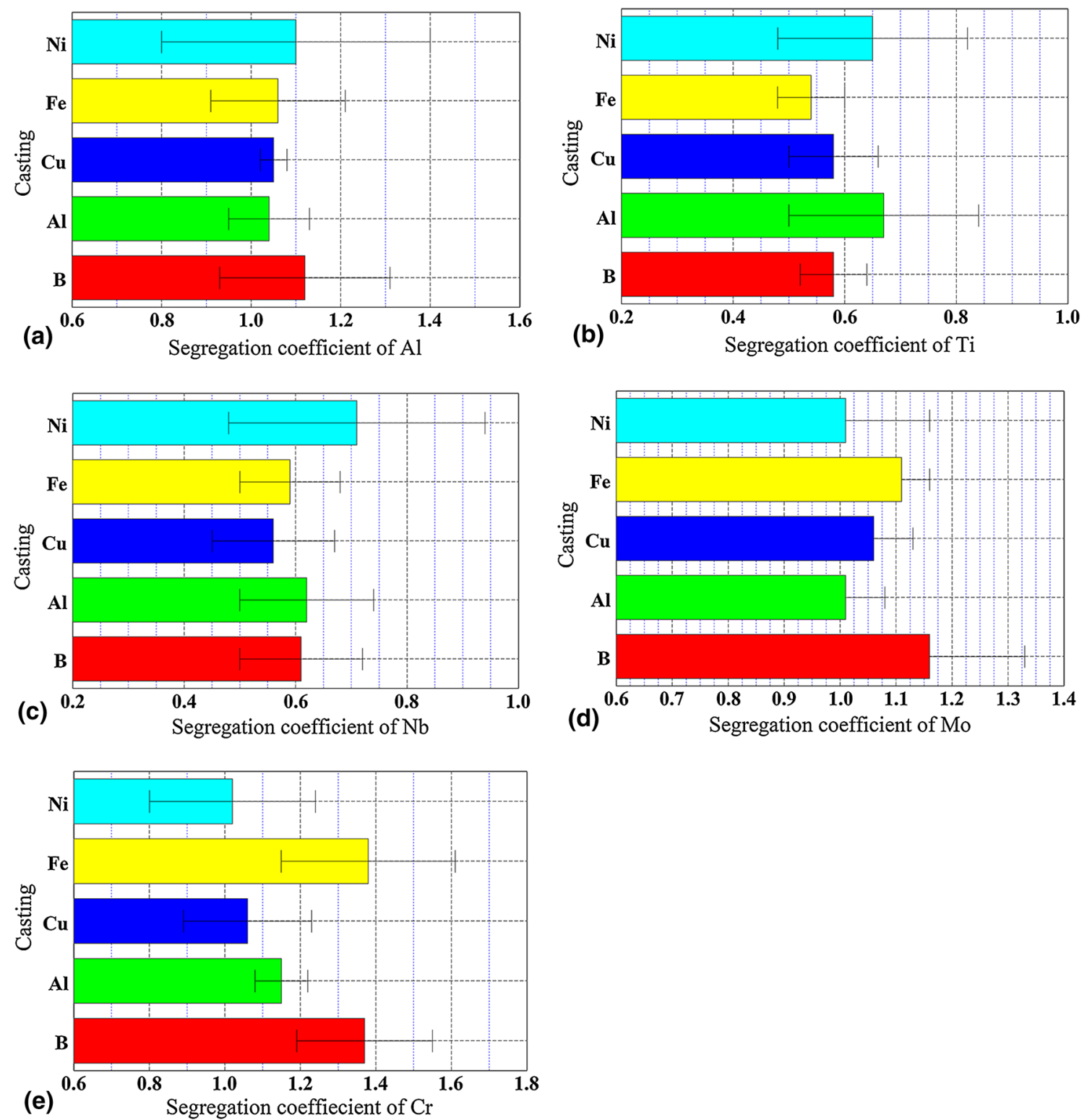

Fig. 10 Segregation coefficient of alloying element in produced castings: (a) $\mathrm{Al}$; (b) $\mathrm{Ti}$; (c) $\mathrm{Nb}$; (d) $\mathrm{Mo}$; (e) $\mathrm{Cr}$

confirmed (Ref 29, 30). Morphology and microanalysis of carbides (MC type) near the compound $\mathrm{Ni}_{7} \mathrm{Zr}_{2}$ show that they are strongly enriched in $\mathrm{Nb}$ and $\mathrm{Zr}$. Such enrichment suggests that during solidification of castings, a ternary eutectic transformation, namely $\mathrm{L}$ (residual with high content of $\mathrm{Zr}$ and C) $\rightarrow \gamma+\mathrm{Ni}_{7} \mathrm{Zr}_{2}+(\mathrm{Nb}, \mathrm{Zr}) \mathrm{C}$. In Fig. 11(c), the microstructure of the lamellar precipitate formed in the close vicinity of eutectic island is illustrated. EDS analysis of this precipitate showed an increased concentration of $\mathrm{Mo}$ and $\mathrm{Cr}$ (Fig. 12c). The total content of these elements exceeded even 80 at.\%. Similar results were obtained in several Ni-based superalloys and indicated that it is a boride (Ref 31-34), e.g., $\mathrm{M}_{5} \mathrm{~B}_{3}$ and $\mathrm{M}_{3} \mathrm{~B}_{2}$. The difference in microstructure and chemical composition between these borides was investigated on the atomic scale resolution by $\mathrm{Hu}$ ( Ref 35 ), who showed that the $\mathrm{M}_{5} \mathrm{~B}_{3}$ borides are strongly enriched in tungsten, while the $M_{3} B_{2}$ in $M o$ and $C r$. Due to lack of $W$ in IN713C, $M_{5} B_{3}$ should not be present and only an $\mathrm{M}_{3} \mathrm{~B}_{2}$ can be formed in IN71C, in accord with TEM observations (Ref 9). Babu (Ref 36) indicated that in chemically complex alloys, eutectic-type reactions can be much more complicated. He suggested that solute enrichment in the last portion of solidifying liquid phase to be inadequate to initiate a typical eutectic reaction due to negligible volume fraction of eutectic $\gamma / \gamma^{\prime}$. In Fig. 11(d) and 12(d), morphology and alloying elements distribution in $M_{3} B_{2}$ adjacent to the $\mathrm{Ni}_{7} \mathrm{Zr}_{2}$ and eutectic island $\gamma / \gamma^{\prime}$ are presented. Such multiphase regions indicate that the formation of the $\gamma / \gamma^{\prime}$ eutectic islands can be accompanied by precipitation from the remaining liquid phase of a ternary eutectic in line with $\mathrm{L}$ (enriched in $\mathrm{Zr}$ and $\mathrm{B}$ ) $\rightarrow \gamma+\mathrm{Ni}_{7} \mathrm{Zr}_{2}+\mathrm{M}_{3} \mathrm{~B}_{2}$. Observations of the morphology of constituents in our IN713C castings were similar to Babu's (Ref 36) interpretation, so can be an explanation of the formation of primary phases in the interdendritic regions. 

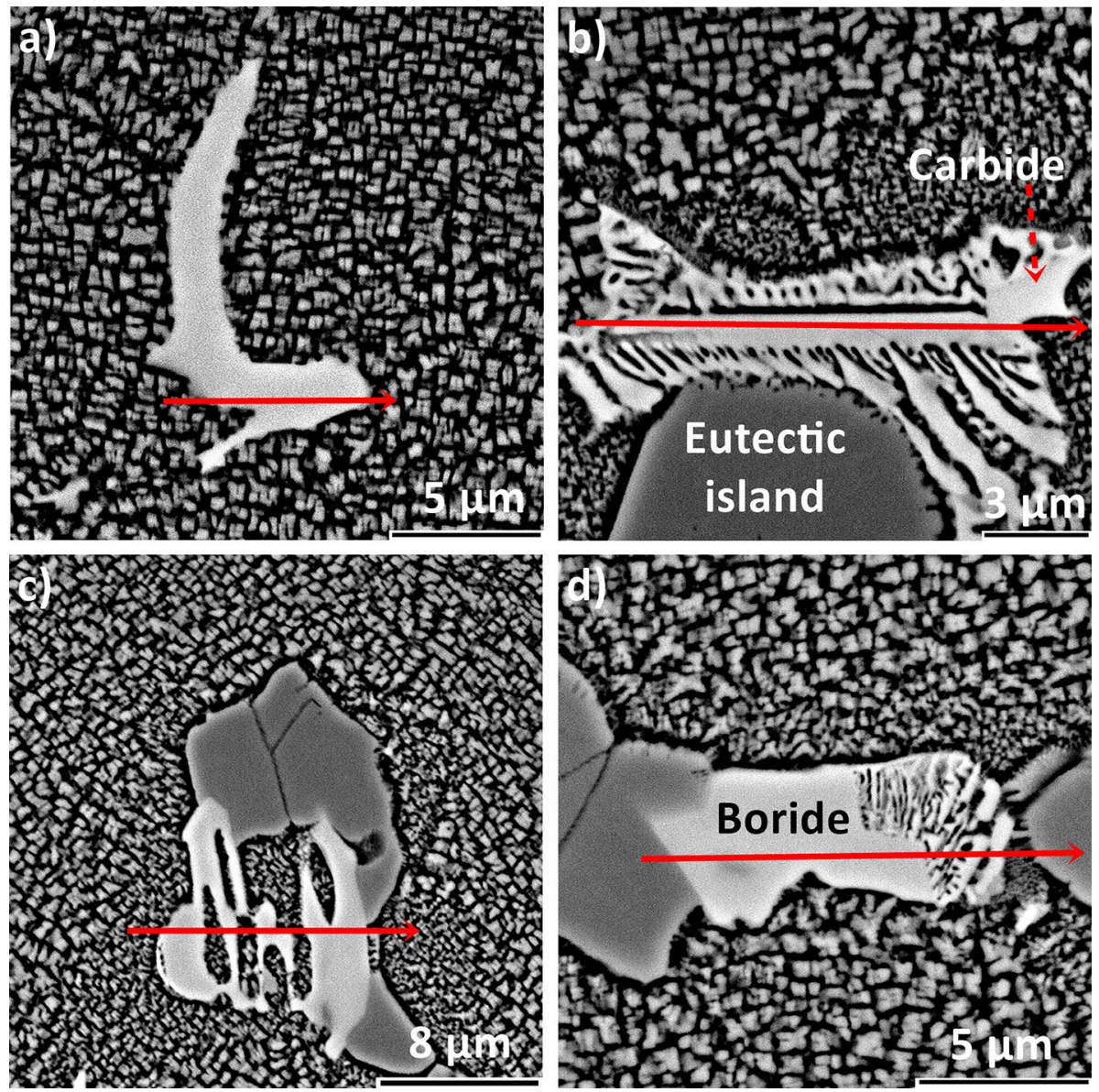

Fig. 11 Morphology of microstructural constituents and location of EDS line: (a) $\mathrm{MC}$ carbide; (b) $\mathrm{MC}$ carbide and $\mathrm{Ni}_{7} \mathrm{Zr}_{2}$; (c) boride $\mathrm{M}_{3} \mathrm{~B}_{2}$; (d) eutectic island $\gamma / \gamma^{\prime}, \mathrm{M}_{3} \mathrm{~B}_{2}$ and $\mathrm{Ni}_{7} \mathrm{Zr}_{2}$

\subsection{Vickers Hardness Measurements}

The average values of Vickers hardness with the standard deviation or all castings are shown in Fig. 13. The casting from the mold not reinforced with fibers, and metal powders had a hardness of $348 \mathrm{HV} 10$. In the remaining castings made in modified molds with the exception of $\mathrm{Cu}$, the hardness was higher. The highest value was achieved in the casting Al: 366 HV10, then in the castings Fe: $361 \mathrm{HV} 10$ and the Ni: 358 HV10. The difference between the highest $(\mathrm{Al})$ and the lowest $(\mathrm{Cu})$ value was $7 \%$, while in comparison with casting $\mathrm{B}$, it was $5 \%$. The highest hardness value was obtained in the casting (Al), strengthened by the highest volume fraction both of the $\gamma^{\prime}$ phase and carbides. The reverse dependence was attributed to the casting $\mathrm{Cu}$. The lowest hardness corresponded with the lowest volume fraction of the $\gamma^{\prime}$ phase and carbides.

\section{Conclusions}

Five kinds of mold were used to fabricate thin-walled Nibased superalloy castings: one was made without strengthening agents, the others contained glass fibers and metal, $\mathrm{Al}, \mathrm{Cu}, \mathrm{Fe}$, $\mathrm{Ni}$, powder particles.

- An increase in green strength was obtained for all modified molds, while the variant with glass fibers and nickel powder achieved the highest bend strength (3.94 MPa). One of the important goals was obtained, namely it is possible to strengthen molds simultaneously through glass fibers and metal powders,

- The addition of glass fibers and Al powder produced a structure with a very large grain size $(7.26 \mathrm{~mm})$. Variants $\mathrm{Cu}$ and $\mathrm{Ni}$ led to grain refinement in comparison with the casting from unmodified mold, respectively, 4.76 and $5.04 \mathrm{~mm}$. The most uniform grain size distribution was found in the casting $\mathrm{Ni}$,

- Measurements of SDAS suggested that addition of metal powders increased the thermal conductivity of modified molds,

- The highest porosity was in the casting $\mathrm{Al}$, namely $0.107 \%$, while the lowest in casting Fe $0.029 \%$. The casting produced in standard form $\mathrm{B}$ had a area fraction of porosity $0.095 \%$,

- The area fraction of the carbides in the casting B was $0.86 \%$, higher in the castings $\mathrm{Al}: 1.09 \%$,

- Microstructure of castings due to the irregular distribution of alloying elements during solidification also affected the smaller size of the $\gamma^{\prime}$ phase precipitates in dendrite arms,

- Volume fraction of $\gamma^{\prime}$ precipitates in all castings was higher in dendrite arms. The highest volume fraction of $\gamma^{\prime}$ precipitates was in casting $\mathrm{Al}, 53.7 \%$ in dendrite arms and $48.5 \%$ in interdendritic spaces. Castings $\mathrm{Fe}$ and $\mathrm{Ni}$ were also characterized by higher volume fraction of $\gamma^{\prime}$ in com- 

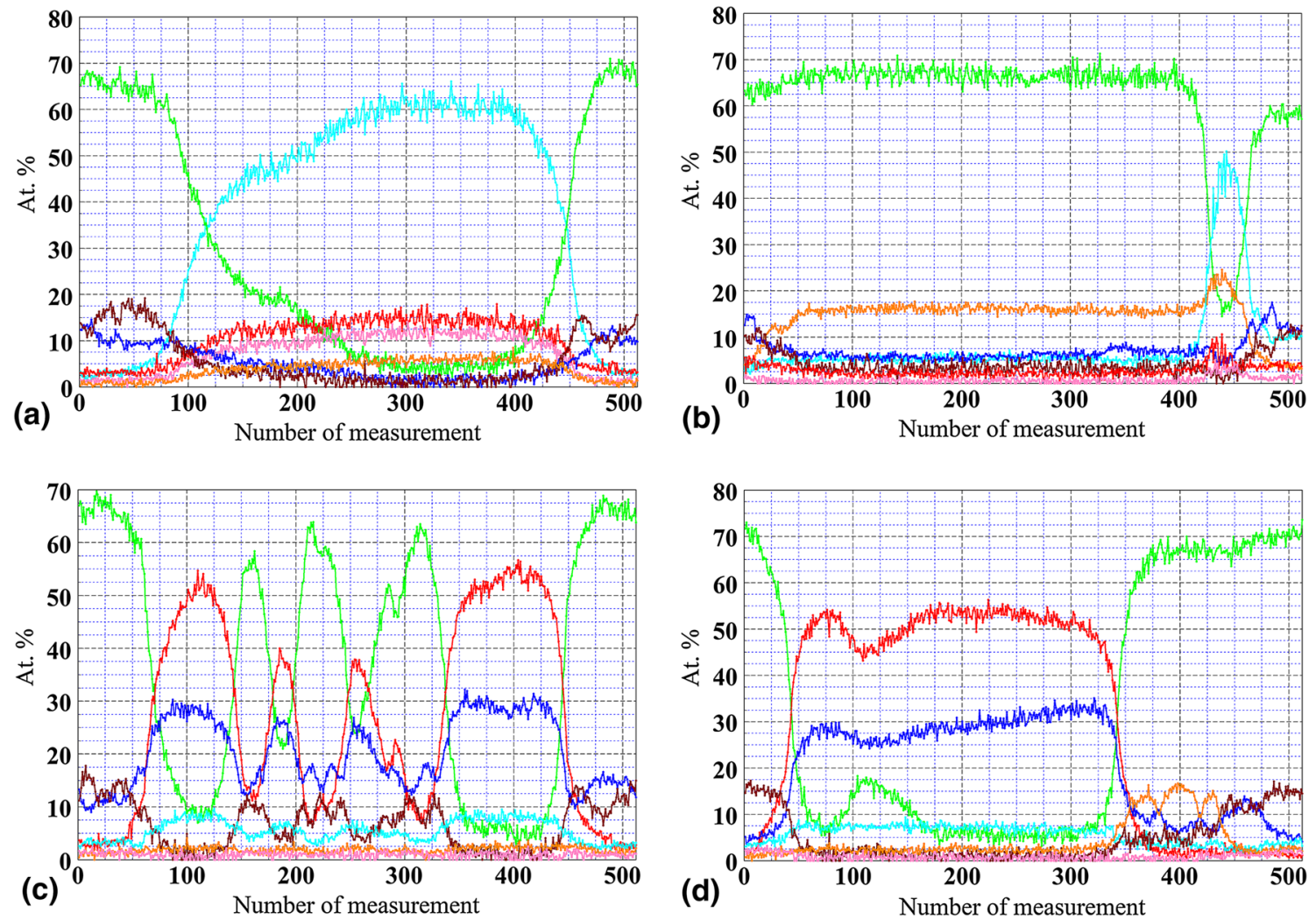

Fig. 12 Results of EDS line analysis: (a) MC carbide; (b) MC carbide and Ni7Zr2; (c) M3B2; (d) eutectic island $\gamma / \gamma^{\prime}$, M3B2 and Ni7Zr2. Colors: bright green $-\mathrm{Ni}$, turquoise $-\mathrm{Nb}$, bronze $-\mathrm{Al}$, blue $-\mathrm{Cr}$, red- $\mathrm{Mo}$, pink $-\mathrm{Ti}$, orange $-\mathrm{Zr}$ (Color figure online)

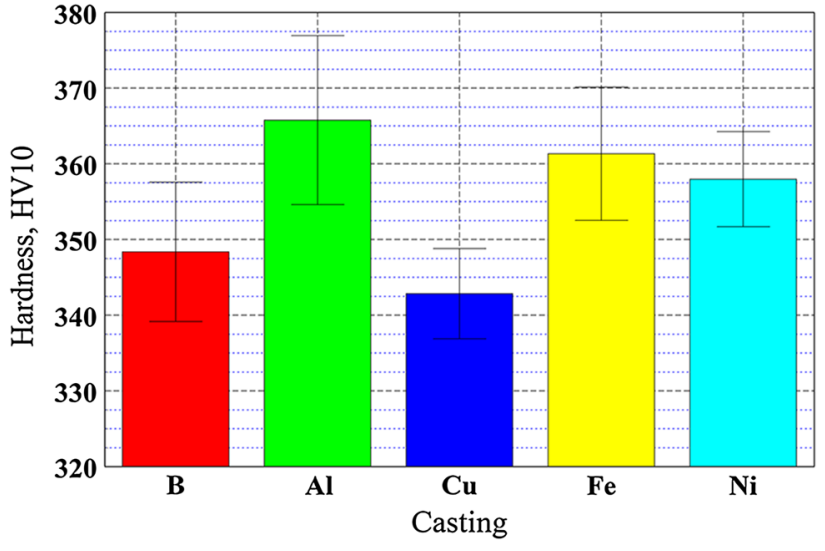

Fig. 13 Hardness of castings

parison with casting from unmodified mold,

- During solidification, of Inconel 713C constituents in interdendritic spaces were created through complex phase transformation. Enrichment of residual interdendritic liquid phase in $\mathrm{Al}$ and Ti led to formation of irregular $\gamma^{\prime}$ in the form of eutectic islands $\gamma / \gamma^{\prime}$. Low solubility of $\mathrm{Zr}$ and B in the $\gamma$ and $\gamma^{\prime}$ caused the formation of $\mathrm{Ni}_{7} \mathrm{Zr}_{2}$ and Morich borides $\mathrm{M}_{3} \mathrm{~B}_{2}$.

- The highest hardness, 366 HV10, was obtained in casting with the highest volume fraction of $\gamma^{\prime}$ and carbides, namely $\mathrm{Al}$, to be compared with that from the unmodified mold, 348 HV 10.

- Results of the microstructural investigation showed that castings produced in the modified molds characterized by the same high quality like in standard mold B,

- Due to the increased strength of molds, the number of layers can be lower; consequently, the drying time during fabrication may be shorter.

\section{Acknowledgments}

The authors gratefully acknowledge the funding by National Centre for Research and Development Poland under Grant LIDER/ 227/L-6/14/NCBR/2015 "New technology for investment casting manufacturing critical engine components with a new generation ceramic materials."

\section{Open Access}

This article is distributed under the terms of the Creative Commons Attribution 4.0 International License (http://creativecommons.org/ licenses/by/4.0/), which permits unrestricted use, distribution, and reproduction in any medium, provided you give appropriate credit to the original author(s) and the source, provide a link to the Creative Commons license, and indicate if changes were made.

\section{References}

1. H. Long et al., Microstructural and Compositional Design of Ni-Based Single Crystalline Superalloys-A Review, J. Alloys Compd., 2018, 743, p 203-220. https://doi.org/10.1016/j.jallcom.2018.01.224 
2. T. Pollock and S. Tin, Nickel-Based Superalloys for Advanced Turbine Engines: Chemistry, Microstructure, and Properties, J. Propuls. Power, 2006, 22(2), p 361-374. https://doi.org/10.2514/1. 18239

3. H. Matysiak et al., The Microstructure Degradation of the IN 713C Nickel-Based Superalloy After the Stress Rupture Tests, J. Matet. Eng. Perform., 2014, 23(9), p 3305-3313. https://doi.org/10.1007/s11665014-1123-4

4. M. Azadi and M. Azadi, Evaluation of High-Temperature Creep Behavior in Inconel 713C Nickel-Based Superalloy Considering Effects of Stress Levels, Mater. Sci. Eng., A, 2017, 689, p 298-305. https://doi.org/10.1016/j.msea.2017.02.066

5. A. Chamanfar et al., Cracking in Fusion Zone and Heat Affected Zone of Electron Beam Welded Inconel-713LC Gas Turbine Blades, Mater. Sci. Eng., A, 2015, 642, p 230-240. https://doi.org/10.1016/j.msea. 2015.06.087

6. M. Coleman et al., Deformation Mechanisms of IN713C Nickel Based Superalloy During Small Punch Testing, Mater. Sci. Eng., A, 2016, 650, p 422-431. https://doi.org/10.1016/j.msea.2015.10.056

7. A. Szczotok and H. Matysiak, Influence of Constituents of Shell Mold on the Morphology and Chemical Composition of Carbides Occurring in IN 713C Superalloy Castings, J. Mater. Eng. Perform., 2014, 23(8), p 2748-2759. https://doi.org/10.1007/s11665-014-1035-3

8. S. Pattnaik and M. Sutar, A Review on Investment Casting Ceramic Shell Building Process, Int. J. Electr. Electron. Comput. Syst., 2017, 6(8), p 399-405

9. H. Matysiak et al., The Influence of the Melt-Pouring Temperature and Inoculant Content on the Macro and Microstructure of the IN713C NiBased Superalloy, J. Miner., 2016, 68(1), p 185-197. https://doi.org/10. 1007/s11837-015-1672-5

10. Y. Venkat et al., Effect of Fine Alumina in Improving Refractoriness of Ceramic Shell Moulds Used for Aeronautical Grade Ni-Base Superalloy Castings, Ceram. Int., 2018, 44, p 12030-12035. https://doi.org/ 10.1016/j.ceramint.2018.03.197

11. D. Szeliga et al., Investigation of Casting-Ceramic Shell Mold Interface Thermal Resistance During Solidification Process of Nickel Based Superalloy, Exp. Therm. Fluid Sci., 2017, 87, p 149-160. https://doi. org/10.1016/j.expthermflusci.2017.04.024

12. S. Jones and C. Yuan, Advances in Shell Moulding for Investment Casting, J. Mater. Process. Technol., 2003, 135, p 258-265. https://doi. org/10.1016/S0924-0136(02)00907-X

13. K. Lü et al., The Interfacial Characteristics and Action Mechanism of Fibre-Reinforced Shell for Investment Casting, Int. J. Adv. Manuf. Technol., 2017, 93, p 2895-2902. https://doi.org/10.1007/s00170-0170735-x

14. K. Lü et al., Properties of Hybrid Fibre Reinforced Shell for Investment Casting, Ceram. Int., 2016, 42, p 15397-15404. https://doi.org/10.10 16/j.ceramint.2016.06.188

15. K. Lü et al., Bending Strength and Fracture Surface Topography of Natural Fiber-Reinforced Shell For Investment Casting Process, China Found., 2016, 13, p 211-216. https://doi.org/10.1007/s41230-016-51 00-4

16. F. Wang et al., Microstructure and Strength of Needle Coke Modified Ceramic Casting Molds, Ceram. Int., 2016, 40, p 479-486. https://doi. org/10.1016/j.ceramint.2013.06.027

17. P. Maity and J. Maity, Development of High Strength Ceramic Shell for Investment Casting, Indian Found. J., 2001, 47(7), p 23-26

18. Ł. Rakoczy and R. Cygan, Analysis of Temperature Distribution in Shell Mould During Thin-Wall Superalloy Casting and its Effect on the Resultant Microstructure, Arch. Civ. Mech. Eng., 2018, 18, p 14411450. https://doi.org/10.1016/j.acme.2018.05.008
19. R. Cygan, Patent Application, Self-Supporting Multi-Layered Ceramic Moulds with the Addition of Metals to Production of Precision Castings. Number P.421560. Warsaw 2017 (in Polish)

20. Y. Wang, Crystallization Kinetics of Calcium Aluminate Glasses Studied by Non-Isothermal Techniques, J. Wuhan Univ. Technol. Mater. Sci. Ed., 2013, 28, p 907-911. https://doi.org/10.1007/s11595013-0791-5

21. D.L. Ride, CRC Handbook of Chemistry and Physics, 95th ed., CRC Press, Boca Raton, 2009

22. C. Yuan et al., On Healing Mechanism of Cast Porosities in Cast Nibased Superalloy by Hot Isostatic Pressing, Energy Materials, The Minerals, Metals and Materials Series, Springer, 2017 https://doi.org/ 10.1007/978-3-319-52333-0 24

23. A. Baldan, Effects of Growth Rate on Carbides and Microporosity in DS200 + Hf Superalloy, J. Mater. Sci., 1991, 26, p 3879-3890. http s://doi.org/10.1007/BF01184986

24. A. Epishin et al., Effects of Segregation in Nickel-Base Superalloys: Dendritic stresses, Superalloys, 2004, 2004, p 537-543. https://doi.org/ 10.7449/2004/Superalloys 2004537543

25. Ł. Rakoczy et al., Evolution of $\gamma^{\prime}$ Morphology and $\gamma / \gamma^{\prime}$ Lattice Misfit in a Nickel-Based Superalloy During Non-Equilibrium Cooling, Int. J. Mater. Res., 2019, 110(1), p 66-69. https://doi.org/10.3139/146.111729

26. F. Zupanic et al., Structure of Continuously Cast Ni-Based Superalloy Inconel 713, J. Alloys Compd., 2001, 329, p 290-297. https://doi.org/ $10.1016 / \mathrm{S} 0925-8388(01) 01676-0$

27. P. Franke, D. Neuschutz, Binary Systems. Part 4: Binary Systems From Mn-Mo to Y-Zr. Landolt-Börnstein-Group IV Physical Chemistry, Numerical Data and Functional Relationships in Science and Technology, vol. 19B4, Springer, Berlin, Heidelberg, 2006

28. H.B. Motejadded et al., Dissolution Mechanism of a Zr Rich Structure in a $\mathrm{Ni}_{3} \mathrm{Al}$ Base Alloy, J. Mater. Sci. Technol., 2011, 27(10), p 885892. https://doi.org/10.1016/S1005-0302(11)60160-6

29. Y. Murata and N. Yukawa, Solid-State Reaction for ZrC Formation in a Zr-Doped Nickel-Based Superalloy, Scr. Metal., 1986, 20(5), p 93-696. https://doi.org/10.1016/0036-9748(86)90493-X

30. O. Ojo et al., Microstructural Study of Weld Fusion Zone of TIG Welded IN 738LC Nickel-Based Superalloy, Scr. Mater., 2004, 51, p 683-688. https://doi.org/10.1016/j.scriptamat.2004.06.013

31. A. Shulga, Boron and Carbon Behavior in the Cast Ni-Base Superalloy EP962, J. Alloys Compd., 2007, 436, p 155-160. https://doi.org/10. 1016/j.jallcom.2006.07.051

32. J. Wei et al., The Effects of Borides on the Mechanical Properties of TLPB Repaired Inconel 738 superalloy, Metall. Trans. A, 2017, 48(10), p 4622-4631

33. X.B. Hu et al., The Wyckoff Positional Order and Polyhedral Intergrowth in the M3B2- and M5B3-Type Boride Precipitated in the Ni-Based Superalloy, Sci. Rep., 2014, 4, p 1-9

34. B. Zhang et al., Precipitation and Evolution of Boride in Diffusion Affected Zone of TLP Joint of MAR-M247 Superalloy, J. Alloys Compd., 2017, 695, p 3202-3210

35. X.B. Hu et al., Atomic-Scale Observation and Analysis of Chemical Ordering in M3B2 and M5B3 Borides, Scr. Mater., 2018, 149, p 274-284

36. S. Babu et al., Atom-Probe Field-Ion Microscopy Investigation of CMSX-4 Ni-Base Superalloy Laser Beam Welds, International Field Emission Society IFES96 Proceedings of the 43rd International Field Emission Symposium, 1996

Publisher's Note Springer Nature remains neutral with regard to jurisdictional claims in published maps and institutional affiliations. 